\title{
Evaluation the aggressive reaction of varicella in young adult immune system compared to children immune response
}

\begin{abstract}
The immune system is a defense system, both children, and adult have the same reaction toward pathogen, uses multiple defense mechanisms evolved to recognize and neutralize pathogens also have the ability to distinguish self from non-self cells, but in case of Varicella-zoster virus (VZV) that cause chicken pox, the immune system reacts differently in young healthy adult usually have an aggressive reaction serious complications can lead to death, compare with children infection is usually mild. This overview illustrates the chickenpox and difference of immune response between the children and young adult toward infection with the varicella-zoster virus.
\end{abstract}

Keywords: chickenpox - varicella zoster virus (VZV), immune system- childrenadult
Volume 7 Issue 3 - 2018

\begin{abstract}
Alaa A Elnour
Department of Medical Lab Science, National Ribat University, Saudi Arabia,
\end{abstract}

Correspondence: Alaa a elnour, Medical Laboratory Scientist, Ibrahim Malik Teaching Hospital National Ribat University, Saudi Arabia, Email alaa.a.elnour@outlook.com

Received: April 18, 2018 | Published: May 10, 2018

\section{Introduction}

Chickenpox, also called varicella, is characterized by itchy red blisters that appear all over the body, is one of the classic diseases of childhood. Is a highly contagious disease caused by the initial infection by varicella zoster virus (VZV) is one of eight herpesviruses its DNA a single, linear, double-stranded molecule, VZV cases both of chickenpox (varicella) and shingles (Herpes zoster), the primary exposure caused chickenpox, and then the virus moved to dorsal root ganglion near the spine, where it remains latent indefinitely.

Chickenpox can be serious, especially for babies, adults, and people with weakened immune systems. The best way to prevent chickenpox is to get the chickenpox vaccine. ${ }^{1}$ Infection in otherwise healthy adults tends to be more severe; some people with serious complications from chickenpox can become so sick that they need to be hospitalized. ${ }^{2}$ Varicella characterizes by a generalized lesions eruption, with other sign and symptoms like fever, loss of appetite and headache, the infection usually mild, but it can be serious and can lead to complications or death. Complication of chickenpox includes bacterial infections of the skin and soft tissues, toxic shock syndrome, infection or inflammation of the brain (encephalitis), dehydration and pneumonia.

Varicella pneumonia is so uncommon that large-scale studies are difficult to conduct and most published studies represent either collection of small case series or retrospective analyses over many years.

Chickenpox can be fatal, especially in immunosuppressed people and adults. ${ }^{3} \mathrm{VZV}$ infection in adults is known to be more severe and associated with increased morbidity. ${ }^{4}$ The case fatality and number of deaths in males were twice those in females. The group of men aged 15-44year. ${ }^{3}$ Many researchers have shown chickenpox may be life threatening for immunosuppressed people, neonate, and normal adults, the severe illness in case of the immunosuppressed patient, because they have a weak immune system and undeveloped immune system in the neonate, in these cases is obvious why these categories get so sick. In the adult case, the immune system is stronger and develops, is not understood why they get serious complications than children which is relatively mild disease in healthy children.

The response of the immune system in case of primary infection with VZV in children and adult (healthy young adult), raising the questions, why varicella is more aggressive in adult in most cases? And why is mild in most children infection?

Perhaps because children have relatively immature immune system the fight action is weaker, opposite adult with a complete system the reaction will be aggressive toward infection. Overall adults have created immunity against a big number of microbes that blood plasma contains a high amount of immunoglobulins and the adult immune system has a good store of memory cells compared, while children are still creating immunity against the things they face. But children have more functioning immune system compared to adults, because immune cells production in adults is reduced compared to children, so if elderly face a new microbe, they may have a severe disease.

But in some aspects, the immune system of the aged organism resembles that of the newborn, both the very young and old immune systems are therefore similarly compromised in coping with a typical viral infection such as influenza, whereas the young (non-pregnant) adult organism seems to be perfectly equipped for this challenge. ${ }^{6}$ There has been an unexplained upward shift in the age distribution of cases over the last 20 years $^{7}$ perhaps it may be the result of less exposure to the varicella zoster virus, the epidemiology of chickenpox appears to be changing.

VZV enters through the respiratory tract and conjunctiva, Chickenpox infection is started in mucosal sites, most of varicella zoster virus inoculated in the upper respiratory tract. The first defense cells have been proposed to encounter the infection is the dendritic cells (DC) of the mucosa ${ }^{8}$ following infection of human tonsillar CD4+ $\mathrm{T}$ cells that express skin homing markers that allow them to transport VZV directly from the lymph node to the skin. ${ }^{8}$ Viral infection can stimulate the release of cytokines and chemokines from inflammatory and noninflammatory cells. 
After The primary infection by VZV, the immune system initially can be delayed or undetected the virus by the developing adaptive immune response, this response occurs due to the incubation period which extends between 10-21 days before the appearance of skin lesions. ${ }^{9}$ Viral infection is known to induce transient autoimmunity in humans, in case of VZV transient antiphospholipid and coagulation protein autoantibodies were common with VZV infection. ${ }^{10}$ The study of varicella zoster virus infection faces a lot of challenges because of the high species specificity and lack of animal to study the infection.

Protection against chickenpox is done by a vaccine, vaccinating a large portion of the population also protects those who are not vaccinated. It also gives in case of exposure to VZV infection to those who are not immune within five days of exposure to chickenpox it prevents most cases of disease. ${ }^{l l}$ Varicella zoster virus (VZV) is not the only pathogen that gives aggressive infection on young adult and mild reaction on children. Hepatitis A Virus (HAV) is in the picornaviruses family, non envelope, a single strand RNA icosahedra virus. Is usually so mild in babies and young children may not even know they have it, but in an adult case about $15 \%$ of people with hepatitis A require hospitalization. Most childhood HAV infections are asymptomatic or mildly symptomatic, without the need for medical care, however, severe symptoms or complications may occur in adults Acute, hepatitis $\mathrm{A}$ in adults has a more severe progression than in children, and may result in fulminant hepatitis, acute kidney injury, and even death in some cases. ${ }^{12}$ There is also Rubivirus (Rubella Virus) is a Togaviridae a single-stranded RNA that is enveloped. The infection often exanthematous disease of infants and children, but typically in the adult case is more severe and associated with more complications in adults.

\section{Conclusion}

Hypothetically, it is possible, that appearance of the excessively strong and robust cell mediated immune response to VZV in adults may be sometimes harmful for the host leading to excessive damage of VZV infected cells which consequently more severe disease and higher percentage of complications. The strongest cell-mediated immune responses to VZV appear to be in early adulthood. Definitive proof is still lacking despite a large body of compelling research data, few hypotheses are made but are they the perfect answer, answering this question may lead to big discoveries, more understanding the mechanism of immunity response in adult and children which lead to better treatment, and may also help to fight another pathogen. However, this requires further study for better understanding of differences in age-specific immunity in children and adults.

\section{Acknowledgment}

None.

\section{Conflict of interest}

Author declares there is no conflict of interest towards this manuscript.

\section{References}

1. Centers for Disease Control and Prevention (CDC). Chickenpox (Varicella). Centers for Disease Control and Prevention.

2. Tunbridge AJ, Breuer J, Jeffery KJ, et al. Chickenpox in adults - clinical management. J Infect. 2008;57(2):95-102.

3. Rawson H, Crampin A, Noah N. Deaths from chickenpox in England and Wales 1995-7: analysis of routine mortality data. BMJ. 2001;323(7321):1091-3.

4. Paul G, Paul BS, Singh G. Unseen face of varicella-zoster infection in adults. Indian J Crit Care Med. 2016;20(12):731-734

5. Katharina Simon, G. A. Evolution of the immune system in humans from infancy to old age. Proc Biol Sci. 282(1821):20143085.

6. Fairley CK, Miller E. Varicella-Zoster Virus Epidemiology: A Changing Scene? J Infect Dis. 1996;174(Suppl 3):S314-9.

7. Abendroth A, Kinchington PR, Slobedman B. Varicella Zoster Virus Immune Evasion Strategies. Curr Top Microbiol Immunol. 2010;342:15571

8. Ku CC, Padilla JA, Grose C, et al. Tropism of varicella-zoster virus for human tonsillar CD4(+) T lymphocytes that express activation, memory, and skin homing markers. J Virol. 76(22):11425-33.

9. Goeijenbier M, van Wissen M, van de Weg C, et al. Review: Viral Infections and Mechanisms of Thrombosis and Bleeding. J Med Virol. 2012;84(10):1680-96.

10. Leung J, Broder KR, Marin M. Severe varicella in persons vaccinated with varicella vaccine (breakthrough varicella): a systematic literature review. Expert Rev Vaccines. 2017;16(4):391-400.

11. Yoon JG, Choi MJ, Yoon JW, et al. Seroprevalence and disease burden of acute hepatitis A in adult population in South Korea. PLoS One 2017;12(10):e0186257.

12. Robert M Kliegman MB. Nelson Textbook of Pediatrics. 19th ed. USA: WB Saunders Co; 2001. 